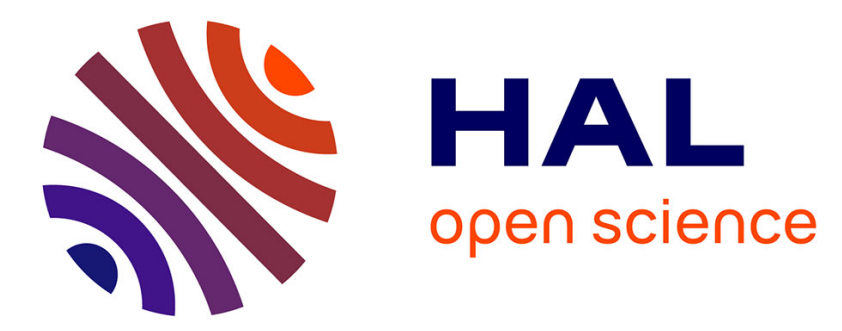

\title{
Modeling and Evaluation of Single Machine Flexibility Using Fuzzy Entropy and Genetic Algorithm Based Approach
}

Toufik Bentrcia, Leïla-Hayet Mouss, Mohamed Djamel Mouss, Mohamed Benbouzid

\section{To cite this version:}

Toufik Bentrcia, Leïla-Hayet Mouss, Mohamed Djamel Mouss, Mohamed Benbouzid. Modeling and Evaluation of Single Machine Flexibility Using Fuzzy Entropy and Genetic Algorithm Based Approach.

The IEEE EFTA 2011, Sep 2011, France. pp.1-8. hal-00654233

\section{HAL Id: hal-00654233 \\ https://hal.science/hal-00654233}

Submitted on 21 Dec 2011

HAL is a multi-disciplinary open access archive for the deposit and dissemination of scientific research documents, whether they are published or not. The documents may come from teaching and research institutions in France or abroad, or from public or private research centers.
L'archive ouverte pluridisciplinaire HAL, est destinée au dépôt et à la diffusion de documents scientifiques de niveau recherche, publiés ou non, émanant des établissements d'enseignement et de recherche français ou étrangers, des laboratoires publics ou privés. 


\section{Modeling and Evaluation of Single Machine Flexibility Using Fuzzy Entropy and Genetic Algorithm Based Approach}

\author{
Toufik Bentrcia \\ Laboratoire d'Automatique et Productique \\ Université Hadj Lakhder -Batna- \\ 05000 Batna, Algérie \\ Toufikmit@yahoo.com \\ Mohamed Djamel Mouss \\ Laboratoire d'Automatique et Productique \\ Université Hadj Lakhder -Batna- \\ 05000 Batna, Algérie \\ D_mouss@yahoo.fr
}

\begin{abstract}
Flexibility has long been recognized as a manufacturing capability that has the potential to impact mainly the competitive position of an organization. The entropy approach, which was extended from information theory, fell in handling problems with incomplete and uncertain data, because it depicts only the stochastic aspects included with measured observations. In order to get a global view, this work proposes a new approach based on fuzzy entropy concept. The development of the fuzzy model results in a set of nonlinear constrained problems to be solved using a metaheuristics method. The applicability of our approach is illustrated through a flexible manufacturing cell. By adopting such framework, both dimensions of uncertainty in system modeling, expressed by stochastic variability and imprecision, can be taken into consideration.
\end{abstract}

\section{Introduction}

There is no doubt among academicians and practitioners that the pressure of global economic crisis will continue to affect decision making process at different levels of a firm [1, 2]. Most managers agree that cost and quality are considered as basic competitive arenas. However, both parameters are not enough to compete effectively in the marketplace. Flexibility will be essential if a firm is to succeed in this increasingly global marketplace [3]. Firms must deliver the best out of their limited resources, they must develop strategies and tactics that ensure their survival and growth. Industrial markets have been tremendously subject to frequent changes concerning many constraints such as product volume [4]. However, in most cases, customers do not accept paying higher prices or waiting longer for products fitting to new constraints. For many operations,

\author{
Leila Hayet Mouss \\ Laboratoire d'Automatique et Productique \\ Université Hadj Lakhder -Batna- \\ 05000 Batna, Algérie \\ Hayet_mouss@yahoo.fr \\ Mohamed Elhachemi Benbouzid \\ Laboratoire d'Ingénierie Mécanique et \\ Electrique, Université de Bretagne \\ Occidentale, 29231 Brest CEDEX 3, France \\ Mohamed_benbouzid@univ-brest.fr
}

the challenge is how to make a compromise between flexibility and one of the following factors: cost, quality, or delivery performance [5].

In a comprehensive survey of the literature, it's reported that more than 50 terms exist for the various types of flexibilities studied. In addition, it's found that several terms refer to the same flexibility type in many cases, and that definitions for flexibility types are often imprecise and contradictory, even for similar terms [6]. To remedy the situation, unified frameworks for classifying flexibility types are a mandatory requirement. Using such frameworks, flexibility types can be defined in a common manner, even if they have been derived based upon different models and assumptions [7, 8].

One metric that has been proposed to measure flexibility in a more mathematical way is entropy, which is based on the premise that flexibility should be a function of the number of available options, and the relative freedoms at which these options can be selected [9]. Although the dominating concept to describe flexibility in entropy based models is stochastic approaches, probabilistic models are not suitable to describe all kinds of uncertainty, but only randomness. The imprecision of data, which is for example as a result of the limited precision of measuring, is not statistical in nature and cannot be described by using probability [10]. The quantification of a scalar quantity introduced into flexibility approaches is likely to be modeled by using fuzzy numbers, which are seen as an extension of ordinary real numbers [11].

Our aim in this work is to propose an approach for modeling of single machine flexibility by using an entropy based measure together with fuzzy set theory to represent both stochastic variability and imprecision. In this approach, the productivity parameter is represented by a triangular fuzzy number. By using the fuzzified parameter and the extension principle, the fuzzy measure 
for single machine flexibility is obtained. Despite that entropy based measures and fuzzy logic have been independently used in modeling and analysis of various types of flexibility in production systems [12-15], the interesting contribution of this paper consists in the suggestion of the use of fuzzy set theory together with an entropy criterion in the modeling of single machine flexibility.

The structure of the paper is as follows: First we have a literature review on entropy and its use as a measure of various types of flexibility. Then, we present the mathematical development of our proposed approach based on the introduction of triangular fuzzy numbers. A numerical example is used to illustrate the application of the approach where obtained results provide a more general framework for decision making compared to the crisp case. Finally some concluding remarks are given. Our proposed approach can be enriched in order to be employed for more complicated situations such as that of aggregate machine system with fuzzy parameters.

\section{Entropy as a measurement criterion}

Entropy was introduced as an additional state variable in the second law of thermodynamics by Rudolf Clausiuis. This law allows the definition of an absolute scale of temperature, that is, one which is independent of the properties of any substance or class of substances [16]. From the fact of commonly today observations, the formulation of the second law was elaborated as: the entropy of the universe tends to a maximum.

The change in entropy $d S$ can be defined empirically in a differential form by [17]:

$$
d S=\frac{d Q}{d T}
$$

where $d Q$ is the quantity of heat flowing from a higher to a lower temperature $(d T)$.

Statistical mechanics has succeeded in providing equations for the calculation of entropy as well as justification for equating entropy with a degree of disorder, where the equilibrium state of a system including a large number of particles is the one with maximum entropy thermodynamically and the most probable state statistically [18].

In information theory, the concept of entropy is used to measure uncertainty in a probability distribution. The well-known Shannon's theorem shows that if we suppose that there is a measure $S$ of the uncertainty and moreover it satisfies the following desirable conditions [19]:

- $S$ is a continuous function of the $p_{i}$.

- If all the $p_{i}$ happen to be equal, then $S$ increases with $n$. Qualitatively, this means that if there are more possibilities, we are more uncertain.

- $S$ is additive.

then $S$ must have the following expression:
$S=-\sum_{i=1}^{n} p_{i} \log p_{i}$

The uncertainty characterizing the competitive environment makes flexibility a valuable weapon for all firms to survive [20]. The development of flexibility measure models using the entropy approach has been widely used to describe various kinds of flexibility in manufacturing systems, particularly routing flexibility, operation flexibility, volume flexibility and expansion flexibility [21-23]. Despite the widespread use of such information based entropy criterion for the measure of flexibility, it shows some limitations due to the lack of considering a weighting factor in the analytical expression of entropy. This factor was defined in terms of many parameters such as: time and/or cost, reliability and efficiency, as indicated in many studies [24-26]. The revised entropy approach obtained by incorporating the efficiency element into the model seems to reflect better the description of the manufacturing flexibility. The revised entropy formula is given by [27]:

$$
S_{j}=-\sum_{i=1}^{n} e_{i j} \rho_{i j} \log \rho_{i j}
$$

where $e_{i j}$ is the efficiency factor and $\rho_{i j}$ represents the selection of the various options, reflecting the freedom of the population. All these $\rho_{i j}$ s are fractions or shares, are positive, $0 \leq \rho_{i j} \leq 1$ and can be normalized such that they add up to unity, $\sum_{i=1}^{n} \rho_{i}=1$, and could be considered as probabilities. In general, the larger the number of available options, the larger the flexibility.

\section{Fuzzy entropy based approach}

Among the earliest attempt at making probability and fuzzy set theory work in concert to deduce a fuzzy entropy measure was made by Zadeh [28], who suggested that the entropy of a fuzzy subset, $A$, of the finite set $\left\{x_{1}, . ., x_{n}\right\}$ with respect to a probability distribution $P=\left\{p_{1}, . ., p_{n}\right\}$ be defined as follows:

$$
S=-\sum_{i=1}^{n} \mu_{A}\left(x_{i}\right) p_{i} \log p_{i}
$$

with $\mu_{A}\left(x_{i}\right)$ the membership function of $A$.

Fuzzy entropy concept emerged later basically in pattern recognition field [29], where many extensions and applications were developed and adopted in order to remedy the many drawbacks related to various aspects of image processing, clustering approaches and cluster validity $[30,31]$.

The flexibility measure formulas of manufacturing systems are too complex to be expressed quantitatively for real cases [32]. Such situation can be reduced by adopting fuzzy set theory based frameworks which resemble human reasoning in order to support 
approximate information. However, a complete depiction of flexibility requires the inclusion of both uncertainty and imprecision in the same framework [33]. In our approach, this process of integration of both sources of ambiguity in flexibility evaluation is achieved through the employment of triangular fuzzy numbers to model uncertainty in parameters which can be considered as probabilities. It's to note that in contrast there is no uncertainty that there is a probability distribution over the space generated by these normalized parameters and the constraint that the probabilities must add to one remains valid [34].

Some basic concepts are needed before presenting the analytical expressions describing our approach, a rich literature about fuzzy set theory is available for more detailed information; see for example [35-36].

Definition 3.1. A triangular shaped fuzzy number noted $\widetilde{N}$ is a normal, convex fuzzy set, on the real line, with a piecewise continuous membership function such that there are three points $\alpha \leq \beta \leq \gamma$ with the following properties:

- $\tilde{N}(x)=0$ for every $x \in[-\infty, \alpha] \cup[\gamma,+\infty]$,

- $\tilde{N}$ is increasing on $[\alpha, \beta]$ and decreasing on $[\beta, \gamma]$,

- $\quad \tilde{N}(\alpha)=\tilde{N}(\gamma)=0$ and $\mu(x)=1$ for every $x=\beta$.

Definition 3.2. Alpha-cuts are slices through a fuzzy set producing regular (non-fuzzy) sets. If $\widetilde{N}$ is a fuzzy subset of some set $\Omega$, then an $\alpha$-cut of $\widetilde{N}$, written $\widetilde{N}[\alpha]$ is defined as:

$\tilde{N}[\alpha]=\{x \in \Omega \mid \tilde{N}(x) \geq \alpha\}$

for all $\alpha, 0 \prec \alpha \leq 1$. The $\alpha=0$ cut is the base of the fuzzy number $\tilde{N}[0]=[\alpha, \gamma]$.

Definition 3.3. If we have a set of $n$ independent variables, then let $z=h\left(x_{1}, . ., x_{i}, . x_{n}\right)$ for $x_{i} \in\left[a_{i}, b_{i}\right]$. We extend $h$ to as:

$$
\left.\widetilde{Z}=\underset{x_{i}}{\operatorname{Sup}} \operatorname{Min}\left(\widetilde{X}_{1}\left(x_{1}\right), . ., \tilde{X}_{i}\left(x_{i}\right), . ., \widetilde{X}_{n}\left(x_{n}\right)\right) h\left(x_{1}, . ., x_{i}, . . x_{n}\right)=z\right\}(6)
$$

for $X_{i}$ a triangular or trapezoidal fuzzy number in $\left[a_{i}, b_{i}\right]$

For $\alpha$-cuts of $\widetilde{Z}$, assuming $h$ is continuous, we have:

$$
\left\{\begin{array}{l}
z^{-}(\alpha)=\operatorname{Min}_{x_{i}}\left\{h\left(x_{1}, . ., x_{i}, . . x_{n}\right) \mid x_{i} \in \tilde{X}_{i}[\alpha]\right\} \\
z^{+}(\alpha)=\operatorname{Max}_{x_{i}}\left\{h\left(x_{1}, . ., x_{i}, . . x_{n}\right) \mid x_{i} \in \tilde{X}_{i}[\alpha]\right\}
\end{array}\right.
$$

The first step towards the elaboration of our fuzzy entropy measure for the evaluation of single machine flexibility consists in the adoption of productive performance of different machines as the initial basic parameter. The elements of the productive matrix $O_{i j}$ represents the productive performance of machine $j$ on performing operation $i$. they can be defined as the outputs of operation $i$ per hour performed by machine $j$.

Since imprecise parameters are treated as imprecise values instead of precise ones, the modeling process will be more powerful and its results more credible as indicated by many real life applications [37]. So, and in order to reach this goal, we substitute
$\widetilde{O}_{i j}=\left(O_{i j 1}, O_{i j 2}, O_{i j 3}\right)$ a triangular fuzzy number, for each $O_{i j}$. The $\alpha$-cut notation can be deduced from the triangular representation by the following transformation:

$\left|O_{i j}^{-}(\alpha), O_{i j}^{+}(\alpha)\right|=\left[\left(O_{i j 2}-O_{i j 1}\right) \alpha+O_{i j 1},\left(O_{i j 2}-O_{i j 3}\right) \alpha+O_{i j 3}\right](8)$

The fuzzy efficiency of machine $j$ on performing operation $i$ noted $\tilde{e}_{i j}$, requires a ranking method for the elements of the productive matrix. In general, for triangular or trapezoidal (shaped) well separated fuzzy numbers, the ordering methodology reduces to the comparison of their cores. For more complicated situations (such as overlapping), a wide range of dedicated approaches is available [38-39].

Therefore, the fuzzy efficiency is obtained by comparing the fuzzy output of a fixed machine $j$ on performing the operation $i$ to the maximum fuzzy output (which depends on the ordering methodology) of the machine that can produce the same operation $i$ in the system, and $\tilde{e}_{i j}$ is given for all $\alpha, 0 \leq \alpha \leq 1$, in $\alpha$-cut notation by:

$$
\widetilde{e}_{i j}[\alpha]=\frac{\widetilde{O}_{i j}[\alpha]}{\widetilde{O}_{i j}^{*}[\alpha]}=\left[O_{i j}^{-}(\alpha), O_{i j}^{+}(\alpha)\right]\left[\frac{1}{O_{i j}^{*+}(\alpha)}, \frac{1}{O_{i j}^{*-}(\alpha)}\right]
$$

where $\widetilde{O}_{i j}^{*}[\alpha]=\operatorname{Max}_{j \in J} \widetilde{O}_{i j}[\alpha]$ and $J$ is the set of machines

in the system. In addition, the condition that $\forall e_{i j} \in \widetilde{e}_{i j}[\alpha]: 0 \leq e_{i j} \leq 1$ should be also satisfied.

Some elementary mathematical developments for the determination of the lower and upper bounds of the fuzzy efficiency give the following expressions:

$$
\left\{\begin{array}{l}
\widetilde{e}_{i j}(\alpha)=\operatorname{Max}\left\{0, \operatorname{Min}\left\{\frac{O_{i j}^{-}(\alpha)}{O_{i j}^{*+}(\alpha)}, \frac{O_{i j}(\alpha)}{O_{i j}^{*-}(\alpha)}, \frac{O_{i j}^{+}(\alpha)}{O_{i j}^{*+}(\alpha)}, \frac{O_{i j}^{+}(\alpha)}{O_{i j}^{*-}(\alpha)}\right\}\right\} \\
\widetilde{e}_{i j}^{+}(\alpha)=\operatorname{Min}\left\{1, \operatorname{Max}\left\{\frac{O_{i j}^{-}(\alpha)}{O_{i j}^{*+}(\alpha)}, \frac{O_{i j}^{-}(\alpha)}{O_{i j}^{*-}(\alpha)}, \frac{O_{i j}^{+}(\alpha)}{O_{i j}^{*+}(\alpha)}, \frac{O_{i j}^{+}(\alpha)}{O_{i j}^{*-}(\alpha)}\right\}\right\}
\end{array}\right.
$$

The following normalization procedure is used to get a fuzzy matrix where the problem of getting a set of values belonging to each column add up to unity is feasible:

$$
\left\{\begin{array}{c}
\tilde{\rho}_{i j}^{-}(\alpha)=\operatorname{Min}_{e_{i j}}\left\{\frac{e_{i j}}{\sum_{i=1}^{n} e_{i j}}\right\} \\
\tilde{\rho}_{i j}^{+}(\alpha)=\operatorname{Max}_{i j}\left\{\frac{e_{i j}}{\sum_{i=1}^{n} e_{i j}}\right\}
\end{array}\right.
$$

subject to the following constraints:

$$
\left\{e_{i j} \in \widetilde{e}_{i j}[\alpha]\right.
$$

Such optimization problem can be expressed in a more convenient form as follows: 


$$
\left\{\begin{array}{l}
\tilde{\rho}_{i j}^{-}(\alpha)=\operatorname{Min}_{e_{i j}, e_{k j}}\left\{\left(1+\left(\sum_{\substack{k \neq i \\
k=1}}^{n} e_{k j} / e_{i j}\right)\right)^{-1}\right\} \\
\tilde{\rho}_{i j}^{+}(\alpha)=\operatorname{Max}_{e_{i j}, e_{k j}}\left\{\left(1+\left(\sum_{\substack{k \neq i \\
k=1}}^{n} e_{k j} / e_{i j}\right)\right)^{-1}\right\}
\end{array}\right.
$$

subject to the same set of constraints.

The solution of the previous set of optimization problems can be proved to have the form:

$$
\left\{\begin{array}{l}
\tilde{\rho}_{i j}^{-}(\alpha)=\frac{e_{i j}^{-}(\alpha)}{\sum_{\substack{k \neq i \\
k=1}}^{n} e_{k j}^{+}(\alpha)+e_{i j}^{-}(\alpha)} \\
\tilde{\rho}_{i j}^{+}(\alpha)=\frac{e_{i j}^{+}(\alpha)}{\sum_{\substack{k \neq i \\
k=1}}^{n} e_{k j}^{-}(\alpha)+e_{i j}^{+}(\alpha)}
\end{array}\right.
$$

Hence, the final formula of our proposed fuzzy entropy is expressed by a set of optimization problems subject to both inequality and equality constraints, the upper and lower bounds of the $\alpha$-cut representation of the fuzzy entropy is given by:

$$
\left\{\begin{array}{l}
S_{j}^{-}(\alpha)=\underset{e_{i j}, \rho_{i j}}{\operatorname{Min}}\left\{-\sum_{i=1}^{n} e_{i j} \rho_{i j} \log \rho_{i j}\right\} \\
S_{j}^{+}(\alpha)=\underset{e_{i j}, \rho_{i j}}{\operatorname{Max}}\left\{-\sum_{i=1}^{n} e_{i j} \rho_{i j} \log \rho_{i j}\right\}
\end{array}\right.
$$

subject to the following constraints:

$$
\left\{\begin{array}{l}
e_{i j} \in \widetilde{e}_{i j}[\alpha] \\
\rho_{i j} \in \widetilde{\rho}_{i j}[\alpha] \\
\sum_{i=1}^{n} \rho_{i j}=1
\end{array}\right.
$$

\section{Simulation and results}

In this section, we consider a flexible manufacturing cell consists of four machines $\left(M_{1}, M_{2}, M_{3}\right.$ and $\left.M_{4}\right)$, each of which is able to perform three operations $\left(O_{1}, O_{2}\right.$ and $\mathrm{O}_{3}$ ). The corresponding matrix of the fuzzy output units per hour is as shown in table 1 . Note that $\alpha=1$ cut value represents the crisp output as provided in [27]. For each operation, the machine which has the highest rate of production is indicated on the same table.
Table 1. Fuzzified output units per hour for the flexible manufacturing cell.

\begin{tabular}{|l|l|c|c|}
\hline & \multicolumn{1}{|c|}{$\mathbf{O}_{1}$} & $\mathbf{O}_{2}$ & $\mathbf{O}_{3}$ \\
\hline $\mathbf{M}_{1}$ & $(79 / 80 / 82)$ & $(79 / 80 / 81)$ & $(75 / 80 / 85)$ \\
\hline $\mathbf{M}_{2}$ & $(88 / 90 / 92)$ & $(57 / 60 / 63)$ & $(86 / 90 / 91)$ \\
\hline $\mathbf{M}_{3}$ & $(95 / 100 / 103)$ & $(68 / 70 / 72)$ & $(69 / 70 / 72)$ \\
\hline $\mathbf{M}_{4}$ & $(36 / 40 / 41)$ & $(39 / 40 / 42)$ & $(37 / 40 / 42)$ \\
\hline
\end{tabular}

The passage from the triangular to the $\alpha$-cut representation is needed because the latter is more friendly and easy to use for computer based simulation and the new representation is shown on table 2 .

Table 2. Representation of the fuzzified output units per hour for the flexible manufacturing cell using alpha-cut notation.

\begin{tabular}{|l|c|c|c|}
\hline & $\mathbf{O}_{1}$ & $\mathbf{O}_{2}$ & $\mathbf{O}_{3}$ \\
\hline $\mathbf{M}_{1}$ & {$[\alpha+79,82-2 \alpha]$} & {$[\alpha+79,81-\alpha]$} & {$[5 \alpha+75,85-5 \alpha]$} \\
\hline $\mathbf{M}_{2}$ & {$[2 \alpha+88,92-2 \alpha]$} & $3 \alpha+57,63-3 \alpha]$ & {$[4 \alpha+86,91-\alpha]$} \\
\hline $\mathbf{M}_{3}$ & {$[5 \alpha+95103-3 \alpha]$} & $2 \alpha+68,72-2 \alpha]$ & {$[\alpha+69,72-2 \alpha]$} \\
\hline $\mathbf{M}_{4}$ & {$[4 \alpha+36,41-\alpha]$} & $\alpha+39,42-2 \alpha]$ & {$[3 \alpha+37,42-2 \alpha]$} \\
\hline
\end{tabular}

The graphical representation of the fuzzy output units per hour for various machines with respect to the first operation is depicted in figure 1.

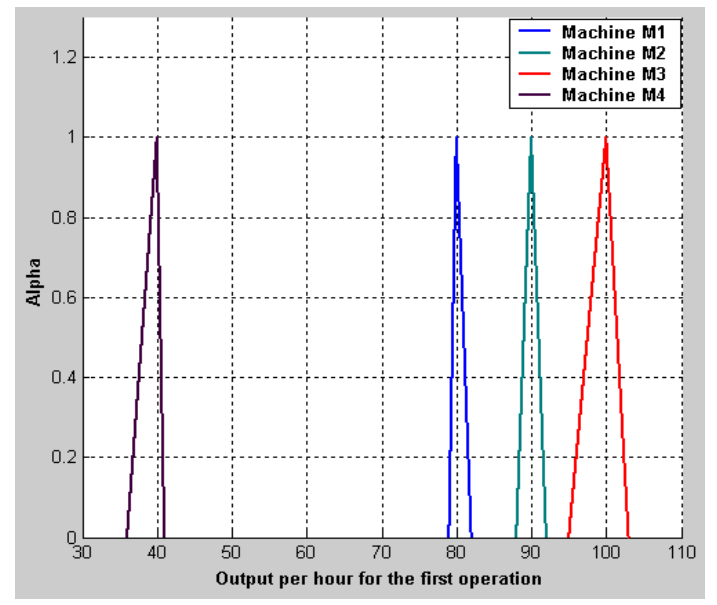

\section{Figure 1. Fuzzy output per hour for different machines according to the first operation.}

The elements of the efficiency matrix are obtained for various machines using interval arithmetic and taking into account the fact that the condition $\forall e_{i j} \in \tilde{e}_{i j}[\alpha]: 0 \leq e_{i j} \leq 1$ should be verified. The latter constraint affects only the machine that produce the maximum fuzzy output for the same operation in the system as indicated in table 3 . 
Table 4. Representation of the obtained fuzzy efficiency matrix for the flexible manufacturing cell using alpha-cut notation.

\begin{tabular}{|l|c|c|c|}
\hline $\mathbf{M}_{1}$ & {$\left[\frac{\alpha+79}{1033 \alpha} ; \frac{82-2 \alpha}{5 \alpha+95}\right]$} & {$\left[\frac{\alpha+79}{81-\alpha} ; 1\right]$} & {$\left[\frac{5 \alpha+75}{91-\alpha} ; \frac{85-5 \alpha}{4 \alpha+86}\right]$} \\
\hline $\mathbf{M}_{2}$ & {$\left[\frac{2 \alpha+88}{1033 \alpha} ; \frac{92-2 \alpha}{5 \alpha+95}\right]$} & {$\left[\frac{3 \alpha+57}{81-\alpha} ; \frac{63-3 \alpha}{\alpha+79}\right]$} & {$\left[\frac{4 \alpha+86}{91-\alpha} ; 1\right]$} \\
\hline $\mathbf{M}_{3}$ & {$\left[\frac{5 \alpha+95}{103-3 \alpha} ; 1\right]$} & {$\left[\frac{2 \alpha+68}{81 \alpha} ; \frac{72-2 \alpha}{\alpha+79}\right]$} & {$\left[\frac{\alpha+69}{91-\alpha} ; \frac{72-2 \alpha}{4 \alpha+86}\right]$} \\
\hline $\mathbf{M}_{4}$ & {$\left[\frac{4 \alpha+36}{1033 \alpha} ; \frac{41-\alpha}{5 \alpha+95}\right]$} & {$\left[\frac{\alpha+39}{81-\alpha} ; \frac{42-2 \alpha}{\alpha+79}\right]$} & {$\left[\frac{3 \alpha+37}{91-\alpha} ; \frac{42-2 \alpha}{4 \alpha+86}\right]$} \\
\hline
\end{tabular}

The graphical representation of the fuzzy efficiency for various machines with respect to the second operation is presented in figure 2 .

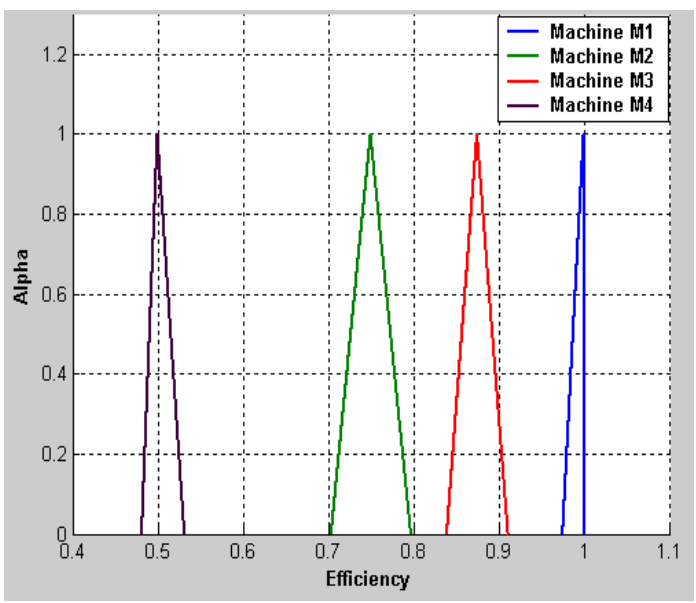

Figure 2. Representation of fuzzy efficiency for different machines according to the second operation.

The calculation of the normalized fuzzy efficiency is straightforward as illustrated below in the case of $\widetilde{\rho}_{14}(\alpha)$ :

$$
\left\{\begin{array}{c}
\tilde{\rho}_{14}^{-}(\alpha)=\frac{\frac{4 \alpha+36}{103-3 \alpha}}{\frac{4 \alpha+36}{103-3 \alpha}+\frac{42-2 \alpha}{\alpha+79}+\frac{42-2 \alpha}{4 \alpha+86}} \\
\tilde{\rho}_{14}^{+}(\alpha)=\frac{\frac{41-\alpha}{5 \alpha+95}}{\frac{41-\alpha}{5 \alpha+95}+\frac{\alpha+39}{81-\alpha}+\frac{3 \alpha+37}{91-\alpha}}
\end{array}\right.
$$

The visualization of various fuzzy normalized efficiencies compared to the third operation is given in figure 3 .

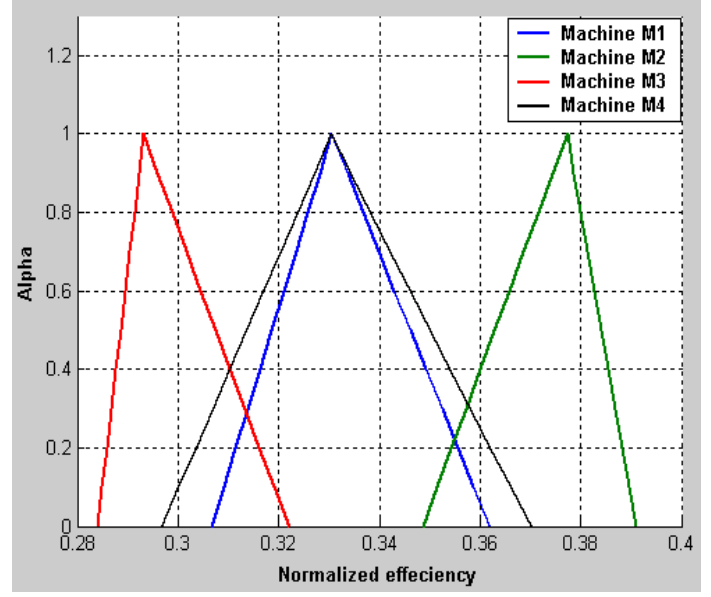

Figure 3. Representation of calculated fuzzy normalized efficiencies according to the third operation.

At this level of development, we have at hand all requirements for the elaboration of our fuzzy entropy measure of single machine flexibility. In order to resolve the associated set of nonlinear constrained problems, a genetic algorithm GA is used. GA combines survival of the fittest among string structures with a structured yet randomized information exchange to form a search algorithm with some of the innovative flair of human search. In every generation, a new set of artificial strings is created using bits and pieces of the fittest of the old; an occasional new part is tried for good measure [40]. In this work, the following values given in table 5 are affected to the main parameters of the algorithm.

Table 6. Values of different parameters used in our genetic algorithm based approach.

\begin{tabular}{|l|c|}
\hline \multicolumn{1}{|c|}{ Parameter } & Value \\
\hline Generation number & 200 \\
\hline Population size & 100 \\
\hline Elite candidates & 5 \\
\hline Crossover fraction & 0.8 \\
\hline Migration fraction & 0.2 \\
\hline Pareto fraction & 0.35 \\
\hline Tolerance & $10^{-6}$ \\
\hline
\end{tabular}

Figure 4 shows the variation of the fitness function with generation in order to determine the lower bound of the fuzzy entropy for the largest $\alpha$-cut $(\alpha=0)$. The steady decrease in the best fitness value solution in each generation until it reaches a best possible value can be attributed to the selection procedure used namely tournament wheel selection. 


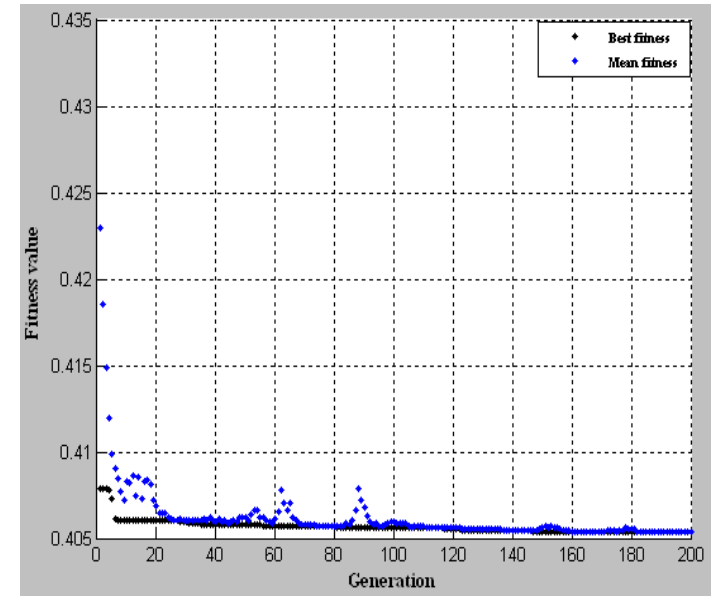

Figure 4. Variation of the objective function with generation for the first machine in case of the minimization problem and alpha $=0$.

In the optimization procedure, the genetic algorithm is applied in an iterative manner to different levels of $\alpha$ cut for various machines. The maximization problems are converted to minimization equivalent ones then resolved appropriately using the same previous methodology. Final optimized values for the upper and lower bounds lead to the following graphical representation of fuzzy entropy for different machines as shown in figure 5 .

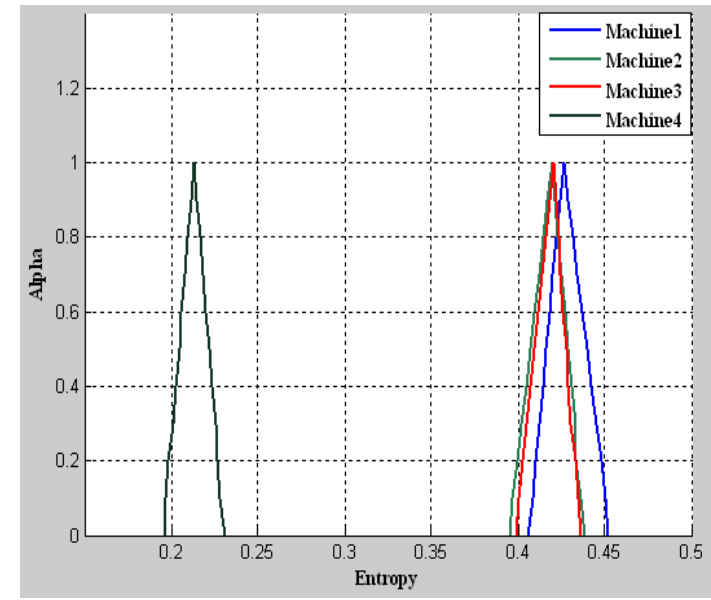

Figure 5. Visualization of the optimized fuzzy entropy using the final values for the upper and lower bounds obtained by GA for all machines under study.

The obtained fuzzy entropies are triangular shaped fuzzy numbers. For this reason, it's preferably to provide only the main $\alpha$-cut values. It's to note that $\alpha=0$ cut value corresponds to the largest interval of uncertainty whereas $\alpha=1$ cut value represents the crisp value as illustrated by table 7 .
Table 8. Main alpha-cut representation of the final fuzzy entropies obtained by the genetic algorithm based optimization.

\begin{tabular}{|c|c|c|}
\hline & $\alpha=0$ & $\alpha=1$ \\
\hline $\mathbf{M}_{1}$ & {$[0.4056 ; 0.4516]$} & 0.4263 \\
\hline $\mathbf{M}_{2}$ & {$[0.3951 ; 0.4382]$} & 0.4194 \\
\hline $\mathbf{M}_{3}$ & {$[0.3985 ; 0.4359]$} & 0.4203 \\
\hline $\mathbf{M}_{4}$ & {$[0.1963 ; 0.2307]$} & 0.2132 \\
\hline
\end{tabular}

Without a significant loss of accuracy, it's possible to elaborate a triangular approximation for the obtained fuzzy entropies. Based on such approximation, the comparison of different machine flexibilities can be made by calculating the following ranking criterion [41] for each machine:

$\operatorname{Val}\left(\tilde{S}_{j}\right)=\int_{0}^{1} \operatorname{Average}\left(\tilde{S}_{j}[\alpha]\right) d \alpha$

where the integrated term is given by:

Average $\left(\widetilde{S}_{j}[\alpha]\right)=\frac{S_{j}^{-}(\alpha)+S_{j}^{+}(\alpha)}{2}$

Obtained values of the ranking criterion used to characterize various machine flexibilities are summarized on the table below.

\section{Table 9. Ranking criterion obtained for different machines.}

\begin{tabular}{|c|c|c|c|c|}
\hline & $\mathbf{M}_{1}$ & $\mathbf{M}_{2}$ & $\mathbf{M}_{3}$ & $\mathbf{M}_{4}$ \\
\hline $\operatorname{Val}(\mathbf{S})$ & 0.8549 & 0.8361 & 0.8375 & 0.4267 \\
\hline
\end{tabular}

Obtained results show clearly that the evaluation of the flexibility of different machines should be using a more general framework built on the basis of fuzzy numbers. This situation demonstrates well that the crisp case with a single value does not enable us to have deductions efficient enough to handle the environment perturbations, where erroneous results can be obtained if significant uncertainties are included within the sampling data used for the assessment of machines flexibility in an industrial process. It's to note also that despite the apparent simplicity of the studied example, our proposed approach can be expanded to more complicated cases such as that of routing flexibility if the number of routes and their associated efficiencies are both evaluated.

\section{Concluding remarks}

In this work, a fuzzy entropy based measure is proposed to improve the capacity of modeling and analysis of flexibility in manufacturing systems. The resulted model takes into account both dimensions of uncertainty which are probabilistic variability and fuzziness. Hence, a set of optimization problems were then formulated using the proposed approach where pertinent parameters were considered simultaneously. 
Despite that the numerical application of this approach was limited to single machine flexibility; our fuzzy entropy approach could be expanded to more complicated situations such as aggregate machine system and manufacturing systems including routing flexibility. It can be concluded that the proposed fuzzy entropy based approach is efficient in dealing with the existence of various simultaneous sources of uncertainty and reduces implicitly to the classical model when considering only crisp data.

\section{References}

[1] M. Melvin, M. P. Taylor, "The Global Financial Crisis: Causes, Threats and Opportunities. Introduction and Overview", Journal of International Money and Finance, Vol.28, pp. 1243-1245, 2009.

[2] S. Riaz, "The Global Financial Crisis: An Institutional Theory Analysis", Critical Perspectives on International Business, Vol.5, No.1/2, pp. 26-35, 2009.

[3] M. Bragliaa, A. Petroni, "Towards a Taxonomy of Search Patterns of Manufacturing Flexibility in Small and Medium-Sized Firms", Omega, Vol.28, pp. 195-213, 2000.

[4] E. P. Jack, A. Raturi, "Sources of Volume Flexibility and their Impact on Performance", Journal of Operations Management, Vol. 20, pp. 519-548, 2002.

[5] L. L. Kostea, M. K. Malhotra, "Trade-offs among the Elements of Flexibility: A Comparison from the Automotive Industry", Omega, Vol.28, pp. 693-710, 2000.

[6] A. K. Sethi, S. P. Sethi, "Flexibility in Manufacturing: A Survey", International Journal of Flexible Manufacturing Systems, Vol.2, pp. 289-328, 1990.

[7] J. P. Shewchuk, C. L. Moodie, "A Framework for Classifying Flexibility Types in Manufacturing", Computers in Industry, Vol.33, pp. 261-269, 1997.

[8] J. P. Shewchuk, C. L. Moodie, "Definition and Classification of Manufacturing of Manufacturing Flexibility Types and Measures", International Journal of Flexible Manufacturing Systems, Vol.10, pp. 325-349, 1998.

[9] G. Chryssolouris, "Flexibility and its Measurement", Annals of the CIRP, Vol.45, No.2, pp. 581-587, 1996.

[10] F. Tüysüz, C. Kahraman, "Modeling a Flexible Manufacturing Cell Using Stochastic Petri Nets with Fuzzy Parameters", Expert Systems with Applications, Vol.37, No.5, pp. 3910-3920, 2010.

[11] C. Kahraman, A. Beskese, D. Ruan, "Measuring Flexibility of Computer Integrated Manufacturing Systems Using Fuzzy Cash Flow Analysis", Information Sciences, Vol.168, pp. 77-94, 2004.

[12] N. C. Tsourveloudis, Y. A. Phillis, "Fuzzy Assessment of Machine Flexibility", IEEE Transactions on Engineering Management, Vol.45, No.1, pp. 78-87, 1998.

[13] N. C. Tsourveloudis, Y. A. Phillis, "Manufacturing Flexibility Measurement: a Fuzzy Logic Framework",
IEEE Transactions on Robotics and Automation, Vol.14, No.4, pp. 513-524, 1998.

[14] A-Y. Chang, "On the Measurement of Routing Flexibility: A Multiple Attribute Approach", International Journal of Production Economics, Vol.109, pp. 122-136, 2007.

[15] A-Y. Chang, "An Attribute Approach to the Measurement of Machine-Group Flexibility", European Journal of Operational Research, Vol.194, pp. 774-786, 2009.

[16] D. Halliday, R. Resnick, Physics, Wiley, New York, 1966.

[17] A. Garrido, "Analyzing the Entropy Concept", Advanced Modeling and Optimization, Vol.11, No.4, pp. 525-530, 2009.

[18] J. S. Dugdale, Entropy and its Physical Meaning, Taylor and Francis, London, 1998.

[19] C. E. Shannon, "A Mathematical Theory of Communication", Bell System Technical Journal, pp. 379-423 and 623-656, 1948.

[20] B. Dreyer, K. Grønhaug, "Uncertainty, Flexibility, and Sustained Competitive Advantage", Journal of Business Research, Vol. 57, pp. 484- 494, 2004.

[21] D. D. Yao, "Material and Information Flows in Flexible Manufacturing Systems", Material Flows, (Special Issue on Flexible Manufacturing Systems), Vol.2, pp. 143149, 1985.

[22] V. Kumar, "Entropic Measurement of Manufacturing Flexibility", International Journal of Production Research, Vol.25, No.7, pp. 957- 966, 1987.

[23] S. Benjaafar, J. J. Talavage, "Process Flexibility in Manufacturing Systems: Models and Measurements", Working paper, School of Industrial Engineering, Purdue University, West Lafayette, IN, August, 1992.

[24] P. Chandra, M. M. Tombak, "Models for the Evaluation of Routing and Machine Flexibility", European Journal of Operations Research, Vol.60, pp. 156- 165, 1992.

[25] H. L. Correa, "Linking Flexibility, Uncertainty and Variability in Manufacturing Systems (Avebury, UK: Ashgate), 1994.

[26] D. M. Upton, "What Really Makes Factories Flexible?", Harvard Business Review, July-August, pp. 74-84, 1995.

[27] A-Y. Chang, D. J. Whitehouse, S-L. Chang and Y-C Hsieh, "An Approach to the Measurement of SingleMachine Flexibility", International Journal of Production. Research, Vol.39, No.8, pp. 1589-1601, 2001.

[28] L. A. Zadeh, "Probability Measures of Fuzzy Events", Journal of Mathematical Analysis and Applications, Vol.32, No.2, pp. 421-427, 1968.

[29] J. Bezdek, Pattern Recognition with Fuzzy Objective Function Algorithms, Plenum, New York, 1981.

[30] H. D. Cheng, Y. H. Chen, Y. Sun, “A Novel Fuzzy Entropy Approach to Image Enhancement and Thresholding”, Signal Processing, Vol.75, pp. 277-301, 1999. 
[31] D. Tran and M. Wagner, "Fuzzy Entropy Clustering", Proc. IEEE 2000 Int'l Conf. Fuzzy Systems, pp. 152-157, 2000.

[32] G. Chryssolouris, Manufacturing Systems: Theory and Practice, Mechanical Engineering Series, Springer, New York, 2006.

[33] L. A. Zadeh, "Discussion: Probability Theory and Fuzzy Logic Are Complementary Rather Than Competitive", Technometrics, Vol.37, pp. 271-276, 1995.

[34] J. J. Buckley, Fuzzy Probabilities: New Approaches and Applications, Studies in Fuzziness and Soft Computing, Springer: Berlin, 2005.

[35] L. A. Zadeh, "Outline of a New Approach to the Analysis of Complex Systems and Decision Processes", IEEE Transactions on Systems, Man, and Cybernetics, Vol.3, No.1, pp. 28-44, 1973.

[36] G. J. Klir, B. Yuan, Fuzzy Sets and Fuzzy Logic: Theory and Applications, Prentice Hall, New Jersey, 1995.
[37] C. Kahraman, M. Gülbay and Ö. Kabak, "Applications of Fuzzy Sets in Industrial Engineering: A Topical Classification", Study in Fuzziness and Soft Computing, Vol.201, pp. 1-55, Springer-Verlag, Berlin Heidelberg, 2006.

[38] N. Ramli, D. Mohamad, "Comparative Analysis of Centroid Methods in Ranking Fuzzy Numbers", European Journal of Scientific Research, Vol.28, No.3, pp. 492-501, 2009.

[39] S. H. Nasseri, M. Soharabi, "Ranking Fuzzy Numbers by Using Radius of Gyration", Australian Journal of Basic and Applied Sciences, Vol.4, No.4, pp. 658-664, 2010.

[40] F. Glover, G. A. Kochenberger, Handbook of Metaheuristics, Kluwer Academic Publishers, New York 2003.

[41] R. R. Yager, "A Procedure for Ordering Fuzzy Subsets of the Unit Interval", Information Sciences, Vol.24, pp. 143-161, 1981. 